\title{
The Influence of Overlap Degree Research on Nozzle Governing Characteristic
}

\author{
Lin $\mathrm{Ma}^{1}$, Jian-qun $\mathrm{Xu}^{{ }^{*}}$, Xue-yu Dong ${ }^{2}$, Tao Yang ${ }^{1}$ \\ ${ }^{1}$ School of Energy and Environment, Southeast University, Nanjing, China \\ ${ }^{2}$ Electrical Power Simulation and Control Engineering Center of Nanjing Institute of Technology, Nanjing, China \\ Email: 331917719@qq.com, "qlj1062@163.com
}

Received January, 2013

\begin{abstract}
To solve the problems existing in the flow characteristics of steam turbine unit, the influence of valve overlap degree on nozzle governing steam turbine had been studied. The combined flow characteristics of given valve overlap degree were obtained for a $600 \mathrm{MW}$ steam turbine unit by the method of theoretical calculation combined with simulation test, and the influence of valve overlap degree on governing stage efficiency and steam chest pressure had been also analyzed. This paper discussed the selection of rational overlap degree and introduced a new method of building model for governing stage efficiency of steam turbine in constant pressure operation condition, which provided theoretical guidance for optimization research on nozzle governing steam turbine operation.
\end{abstract}

Keywords: Overlap Degree; Flow Characteristics; Valve Point; Governing Stage Efficiency; Operation Mode

\section{Introduction}

In China, many $600 \mathrm{MW}$ and above units are widely using DEH control system, which provides the function of valve management and the operation control for single valve to sequence valve. Unfortunately, due to the effect of some factors, site installation, for example, there are differences between actual flow characteristics and initialize flow characteristics in DEH system. In this case, it will lead to load disturbance and more security risks with operation under design condition [1]. Furthermore, the complexity is increased by the fact that a turbine is generally operated by two or four control valves which do not necessarily work parallel over the complete operational range. Therefore, in order to ensure the operation of single valve to sequence valve can be stably switched, certain overlap degree is needed when control valves open or close. However, big overlap degree will cause large throttling losses and low thermal efficiency. Conversely, small overlap degree will cause poor linearity of combined flow characteristics, which is disadvantageous to electric power control. Thus, rational overlap degree should be set before the function of sequence valve put into operation, in order to ensure the security and reduce the influence on important parameters (vibration, bearing temperature, etc) of steam turbine during the switching process.

The value of overlap degree not only directly affects

"Corresponding author. static characteristics of steam distribution mechanism, but also affects governing stage efficiency. Therefore, the selection of rational overlap degree to further improve the economic efficiency is of great significance.

The aim of this paper is to discuss the selection of rational overlap degree, and analyze the influence of overlap degree on governing stage efficiency and steam chest pressure.

\section{Valve Overlap Degree}

To the "sequence valve" operation mode with nozzle governing units, the subsequent valve didn't open until the previous valve opened completely, its flow characteristics can be illustrated by the following Figure 1, the solid cam line. In this case, the static characteristics of speed variation rate were also cam curve, it was not conform to the design requirements of control system. Thus, it is necessary to find certain valve overlap degree so as to compensate for the previous valve's nonlinear characteristics, the dotted line as shown in Figure 1. Generally, valve overlap degree is expressed as $\zeta_{\mathrm{p}}$.

\section{The Selection of Overlap Degree}

Valve flow characteristics must be necessary so as to obtain rational overlap degree. Assuming that the individual valve characteristic is known, the key problem is how to determine the flow distribution among semi-open valves[2]. From the point of mathematical view, building 
mathematical model of overlap degree, in fact, aims at taking a nonlinear distribution upon steam mass flow through control valves.

Nevertheless, due to the existing variable condition calculation without considering the overlap degree, additionally, the actual flow characteristics are too hard to compute. To comply with this task, this paper present a method of theoretical calculation combined with simulation test, look as the following Figure 2:

\section{Application and Analysis}

An application example is provided with a $600 \mathrm{MW}$ steam turbine unit.

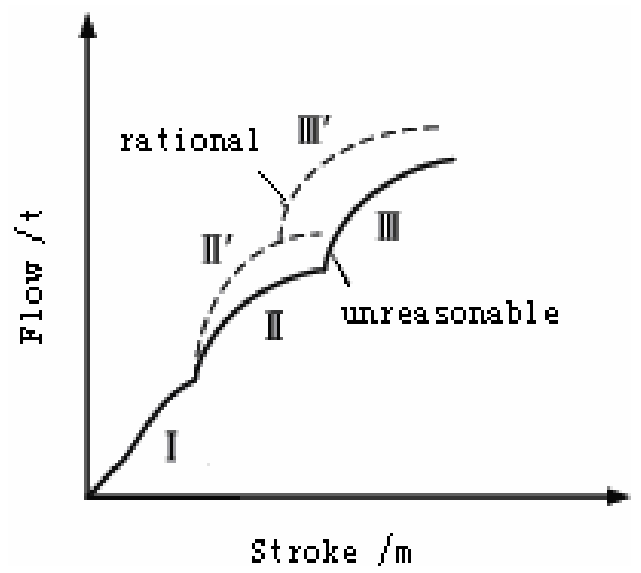

Figure 1. Flow characteristics of control valves.

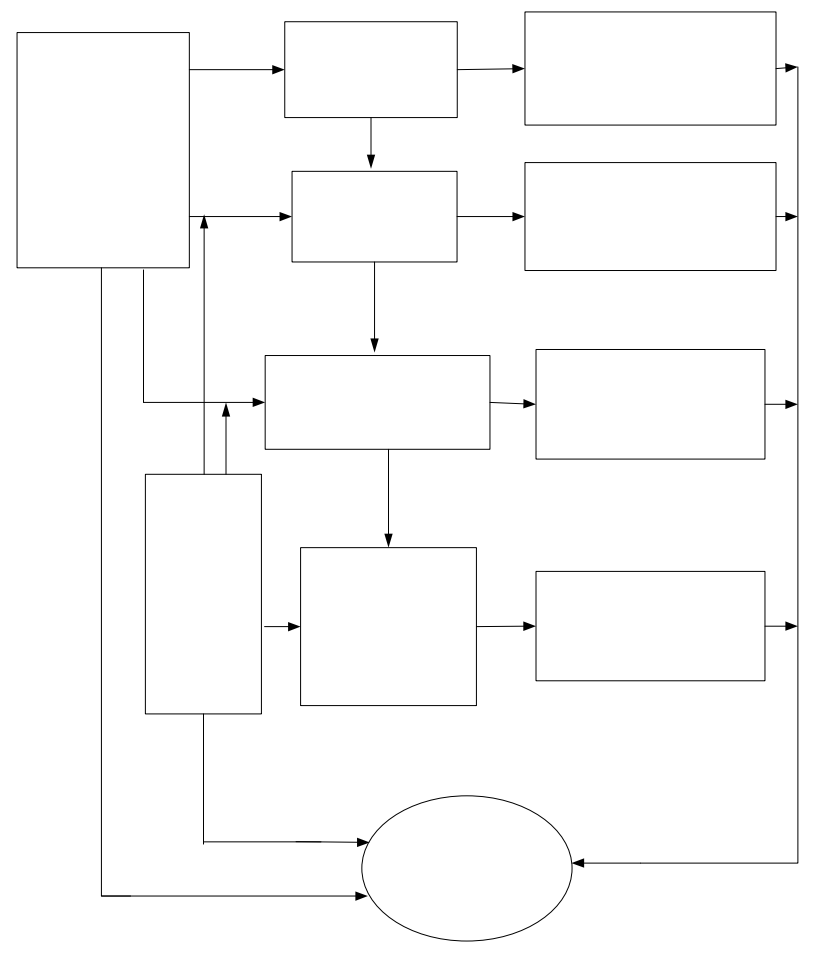

Figure 2. Flow chart of research method. a) In practice, according to the concept of overlap degree, the thermodynamic calculating program with given overlap degree for governing stage in variable operation condition were compiled together with the simulation test by means of APROS simulation platform for constant pressure operation $(16.7 \mathrm{MPa})$ with four valves[3,4]. The percentage, here, refers to the flow ratio that main steam mass flow in variable condition and rated condition. Valve overlap degree are, respectively, 0, 0.121, 0.278, the corresponding valve combined flow characteristics and pressure characteristics are separately indicated by Figures 3(a) and (b).

In Figure 3 above:

1) The linearity of combined flow characteristics are worst when valve overlap degree is zero, then, the linearity turns better with the increase of overlap degree, as shown in Figure 3(a).

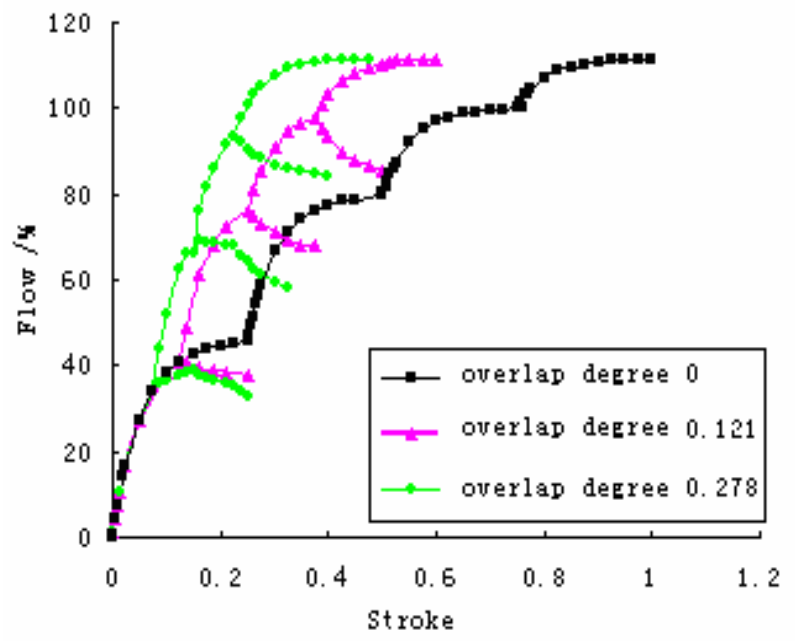

(a)

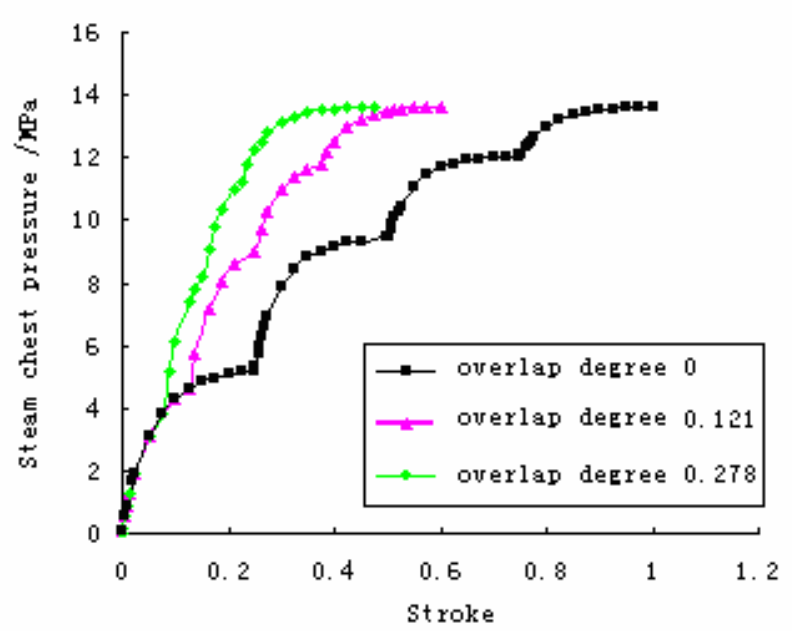

(b)

Figure 3. (a) Valve combined flow characteristics; (b) Pressure characteristics. 
2) The pressure characteristics are precisely shown by Figure 3 (b): the steam chest pressure is mostly proportional to the change of total steam mass flow. The pressure after governing stage at valve point fluctuates enormously.

b) Combining the ideas of the previous sections, the variable condition calculating program for nozzle governing $600 \mathrm{MW}$ steam turbine in constant pressure (16.7 $\mathrm{MPa}$ ) was compiled [5-7]. According to the thermodynamic calculation, the change law of relative internal efficiency for governing stage is accurately explained by the following Figure 4.

In Figure 4 above:

1) Sequence valve operation mode in constant pressure condition: when the overlap degree is zero, the corresponding governing stage efficiency is the highest, but getting lower with the increase of overlap degree.

2) Sequence valve operation mode in constant pressure condition: the tendency of efficiency curve is parabolic shape in valve point condition, and getting lower with the decrease of the valve point.

Relative internal efficiency at valve point $\eta_{\text {ri }}$, can be expressed as the function of main steam mass flow $G$, main steam pressure $\mathrm{p}_{0}$, overlap degree $\zeta_{\mathrm{p}}$ :

$$
\eta_{r i}=f\left(G, \zeta_{p}, p_{0}\right)
$$

Assuming $\zeta_{\mathrm{p}}, \mathrm{p}_{0}$ are given:

$$
\eta_{r i}=f(G)
$$

Thus, parabolic equation can be obtained by fitting the efficiency curve of valve point:

$$
\eta_{r i}=f(G)=e_{1} G^{2}+e_{2} G+e_{3}
$$

Since the coefficients are linked to $\zeta_{\mathrm{p}}, \mathrm{p}_{0}$ and governing stage structure, they can be determined by the design of units.

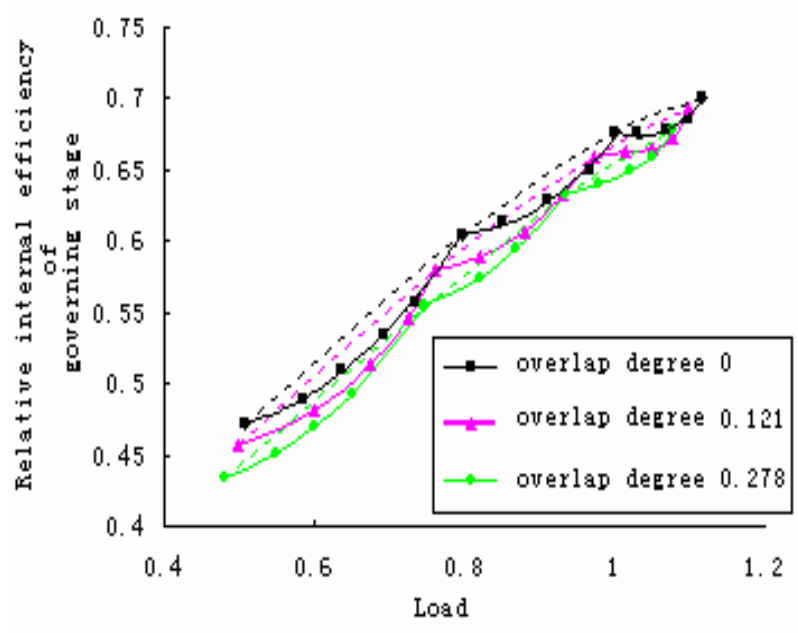

Figure 4. The change law of relative internal efficiency.
3) Sequence valve operation mode in constant pressure condition: the efficiency of semi-open valves condition among valve points are approximately tend to sine curve, which was caused by throttling losses.

Thus, $\eta_{\mathrm{ri}}$ can be determined by $\mathrm{G}, \mathrm{p}_{0}, \zeta_{\mathrm{p}}$ and flow area A:

$$
\eta_{r i}=f\left(G, A, \zeta_{p}, p_{0}\right)
$$

Since flow area $\mathrm{A}$ is a single-valued function of valve opening degree $\mathrm{D}$. When $\zeta_{\mathrm{p}}, \mathrm{p}_{0}$ are given, $\eta_{\mathrm{ri}}$ can be expressed as:

$$
\eta_{r i}=f(G, D)
$$

According to the research above, a simplified model, which is uniquely linked to the operation mode, $\mathrm{G}$ and $\mathrm{D}$, can be inverted:

$$
\eta_{r i}=f(G) \sin (a D+b)+c
$$

Where $\mathrm{a}, \mathrm{b}$ and $\mathrm{c}$ are all constant

Consequently, $\eta_{r i}$ can be calculated quickly by the simplified model, especially when design parameters are known.

The subsequent table displays a computational comparison between the simplified model and thermodynamic calculation (overlap degree is zero, for example), as shown in Table 1.

Table 1 shows the accuracy of simplified model, for the maximum error is $0.472 \%$. The new mathematical model has been successfully implemented on fast calculation of efficiency for governing stage in constant pressure operation of sequence valve.

\section{Consequence}

1) Unreasonable overlap degree will affect static characteristics of steam distribution mechanism, may cause system operation unstable. Rational overlap degree can improve governing stage efficiency. Therefore, the selection of rational overlap degree should consider better linearity and higher efficiency as criterion.

Table 1. Efficiency comparison.

\begin{tabular}{ccccc}
\hline Value operation & Load & $\begin{array}{c}\text { Efficiency of } \\
\text { simplified } \\
\text { model /\% }\end{array}$ & $\begin{array}{c}\text { Efficiency of } \\
\text { thermodynamic } \\
\text { calculation /\% }\end{array}$ & $\begin{array}{c}\text { Absolute } \\
\text { error/\% }\end{array}$ \\
\hline & 0.5851 & 49.014 & 48.789 & 0.225 \\
1 fully & 0.6372 & 50.640 & 51.091 & -0.441 \\
open 1 throttle & 0.6922 & 53.953 & 53.511 & 0.442 \\
& 0.7331 & 56.161 & 55.689 & 0.472 \\
2 fully & 0.8512 & 61.612 & 61.312 & 0.300 \\
open 1 throttle & 0.9113 & 63.088 & 62.788 & 0.300 \\
& 0.9688 & 64.808 & 65.121 & -0.313 \\
3 fully & 1.0292 & 67.886 & 67.543 & 0.343 \\
open 1 throttle & 1.0694 & 68.036 & 67.832 & 0.204 \\
\hline & 1.1123 & 68.229 & 68.610 & -0.381 \\
\hline
\end{tabular}


2) Simplified model for governing stage efficiency has high feasibility and accuracy. The research's thought and method provided governing stage operation with theoretical guidance for economic evaluation standard.

\section{Conclusions}

1) This paper adopted the method of theoretical calculation combined with simulation test to study overlap degree that was different from other previous research work, which is convenient for optimization research on nozzle governing steam turbine.

2) This paper introduced valve point operation condition to take a 'multiple' comparison with higher accuracy, which can more accurately reflect the influence of overlap degree.

3) This paper determined the pressure characteristics and analyzed the influence of overlap degree on steam chest pressure. The pressure characteristics were helpful to reflect the importance of rational overlap degree.

4) This paper put forward a new simplified model based on nozzle governing $600 \mathrm{MW}$ steam turbine unit, provided theoretical reference for different capacity units.

\section{REFERENCES}

[1] G. Zimmer and C. H. Florian, "On Linearizing The Steam Mass Flow Relative To The Controller Output," Proceedings of The ASME 2011 Power Conference, 2011.

[2] Y. Li, L.-K. Lu and S. Liu, "Research on Calculation Method of Governing Stage Off-design Conditions in Consideration of Governing Valve Overlap Degree," APPEEC, 2010.

[3] Q. J. Li, P. Huo and L. K. Zheng, "Test Method of Ratedsliding Pressure Operation Mode for Domestic $600 \mathrm{MW}$ Steam Turbines," Turbine technology, 2009, No. 5, pp. 386-389.

[4] Fernández and M. Álvarez, "A New Model for the Analysis and Simulation of Steam Turbines at Partial and Full load," Journal of Engineering for Gas Turbines and Power, 2011.

[5] K. Jonshagen and M. Genrup, "Improved Load Control for a Steam Cycle Combined Heat and Power Plant," Energy, Vol. 35, 2010, pp. 1694-1700. doi:10.1016/j.energy.2009.12.019

[6] Y. L. Zhao, Z. F. Qin and X. G. Shi, "Research of 600 MW Steam Turbine Operation Solution of Switching Single-valve to Sequential Valve," Thermal Turbine, Vol. 36, No. 3, 2007, pp. 71-75.

[7] L. Gao and Y. P. Dai, "Rotor Dynamic Analysis on Partial Admission Control Stage in a Large Power Steam Turbine," ASME Turbo Expo 2010: Power for Land, Sea and Air, June 14-18, 2010, Glasgow, UK, pp.1-7. 